\title{
Systematics and taxonomy of the arbuscular endomycorrhizal fungi (Glomales) - a possible way forward
}

\author{
C Walker \\ Forestry Commission, The Forestry Authority, Northern Research Station, Roslin, Midlothian EH25, 9SY, UK \\ (COST Meeting, 21-23 May 1992, Dijon, France)
}

\begin{abstract}
Summary - The identification of plants belonging to mycorrhizal symbioses is easy, but that of the fungal partners is in an underdeveloped state. The history of the taxonomy of the Glomales is presented here, including that of genera, species, types. This taxonomy can nowadays be based upon phylogeny and morphological, ontogenic, biological, molecular and genetic studies.
\end{abstract}

\section{taxonomy / endomycorrhiza / fungus}

Résumé - Systématique et taxonomie des Glomales. La possibilité d'un bond en avant. L'identification des plantes appartenant à une symbiose mycorrhizienne est aisée mais celle du champignon partenaire est encore délicate à cause de l'état de sous-développement de la taxonomie de ces champignons. L'histoire de la taxonomie des Glomales est ici présentée, incluant la présentation des genres, des espèces et des types. Cette taxonomie peut aujourd'hui se baser sur la phylogénie et sur des études morphologiques, ontogéniques, biologiques moléculaires et génétiques.

\section{taxonomie / endomycorhize / champignon}

\section{INTRODUCTION}

The justification for an article on taxonomy in a journal edition dedicated to tissue culture and mycorrhizas is 2-fold. Firstly, tissue culture techniques may help to solve some of the problems with systematics and taxonomy of arbuscular mycorrhizal fungi. Secondly, it is vital in the study of any symbiosis that equal attention be paid to the identity of all partners; identification of the plant in an arbuscular mycorrhizal partnership is relatively easy, whereas the present underdeveloped state of taxonomy of the mycobionts tends to lead to misidentification and confusion. Different fungi can have markedly different effects on plant growth, and its is "... important that... (they)... be correctly identified, particularly in those experiments pertaining to the possible agricultural exploitation of their beneficial effects..." (Hall, 1987).

Taxonomy and systematics are essential underpinnings to the work of the biologist (Burdsall,
1990), but they must have a sound biological base. Because the arbuscular-mycorrhizal fungi in the Glomales have not yet been successfully cultured axenically, they are usually grown in pots with plants. The pots are normally open to the elements, and the substrate is sterile for only a short time at best. Advances in tissue culture (in particular, in transformed root organ culture) have allowed species of arbuscular mycorrhizal fungi to be grown in vitro, permitting detailed observations on the development of spores and other structures (Bécard and Piché, 1989).

There are presently $\approx 130$ species recognised in the Glomales (Walker and Trappe, 1992). More than 65 had been described by 1983; but taxonomic concepts have advanced (eg Walker, 1983; Morton, 1987), and only a few have been re-described using modern concepts and terminology (eg Koske and Walker, 1985; Walker and Koske, 1987). Consequently, matching new collections with old descriptions often leads to insurmountable difficulties in identification. 


\section{HISTORICAL}

The order Endogonales formalised by Benjamin (1979) had a single family, the Endogonaceae, containing the zygosporic Endogone, as well as the arbuscular mycorrhizal fungi, and some other genera since classified as belonging elsewhere (table I). From this, the order Glomales was defined to encompass only fungi either known or presumed to form arbuscular mycorrhizae with plants (Morton and Benny, 1990). The order Endogonales now contains only 2 genera, Endogone and Sclerogone still in the one family, the Endogonaceae. The remainder of the species in the Endogonales sensu lato were transferred to 3 families in the Glomales (table I). The Endogonales, consequently, have come to be of reduced importance to plant scientists, even though at least 2 Endogone spp form ectomycorrhizae with conifers. Their relationship with the Glomales is uncertain, but is unlikely to be close. This paper is intended to deal only with the fungi that have the potential to form arbuscular mycorrhizal symbioses, and therefore there will be no further discussion of the Endogonales sensu stricto, except in a historical context.

Table I. Endogonales and Glomales: old and new ordinal and family structure.

Old structure : one-time members, Complexipes, Modicalla, and Glaziella are excluded.

Order: Endogonales (Gerdemann and Trappe, 1974; Benjamin, 1979; Warcup, 1990)

Family: Endogonaceae

$\begin{aligned} & \text { Genera: } \text { Eridogone } \\ & \text { Sclerogone } \\ & \text { Glomus } \\ & \text { Sclerocystis } \\ & \text { Acaulospora } \\ & \text { Entrophospora } \\ & \text { Gigaspora } \\ & \text { Scutellospora }\end{aligned}$

New structure (after Morton and Benny, 1990)

Order : Endogonales

Family: Endogonaceae

Genera: Endogone, Sclerogone

Order : Glomales

Suborder: Glominaeae

Family : Glomaceae

Genera: Glomus, Sclerocystis

Family : Acaulosporaceae

Genera: Acaulospora, Entrophospora

Suborder : Gigasporaceae

Family: Gigasporaceae

Genera : Gigaspora, Scutellospora
The first revision of the Endogonaceae sensu lato was published long before their symbiotic relationships were understood (Thaxter, 1922). After the recognition of the relationship between arbuscular mycorrhizas and the spores of some of the then Endogone spp (Mosse, 1953), a new phase of descriptive (Mosse and Bowen, 1968) and taxonomic (Gerdemann and Nicolson, 1963) work began, culminating, almost $20 \mathrm{yr}$ ago, in the seminal work on the Endogonaceae in the Pacific Northwest (Gerdemann and Trappe, 1974). Although published merely as a local survey, it established the foundations upon which taxonomic concepts are still largely based.

The taxonomy of fungi in the Glomales is founded principally on the structure of their spores or sporocarps. This has been criticised on the grounds that the "whole fungus" approach would be preferable (Walker, 1985), but it appears that theoretically some of this criticism was unfounded, since spore morphology is genetically disconnected from other perhaps more plastic aspects of these fungi (Morton, 1990a). The apparent simplicity of spore structure might seem to be a barrier to creating a workable taxonomy, but as many as 115 character states (though not all associated with spores) have been used in separating species of the Endogonales sensu lato (Hall, 1983). Such characters were used to construct a dichotomous key (Hall and Fish, 1979) and later a synoptic key (Trappe, 1982). Unfortunately, both keys inevitably suffered from being based partly on descriptions in the literature. The progress of taxonomic ideas has resulted in an increasing reliance on some characteristics such as spore wall structure (Walker, 1983) and a reduction in emphasis on others such as sporocarp production, appearance of spore contents, and reaction to stains such as cotton blue (Morton, 1988). Because of this, many of the older descriptions are inadequate and comparisons with new collections are difficult. Theoretically, examination of type specimens should solve this problem, but many are in such a poor state of preservation that they are of little use. The keys were often based, therefore, on incomplete and sometimes erroneous data.

In a discussion of the taxonomy and phylogeny of the Endogonales sensu lato, Berch (1986) pointed out some areas of controversy, and suggested potentially fruitful research topics. She criticised some of the terminology (eg, walls (Walker, 1983); sporiferous saccule (Walker et al, 1984)), although her proposed alternatives did not find wide acceptance. The most recent sum- 
mary of the characteristics used in species description is very thorough (Morton, 1988). It provides an excellent synthesis of previous work, and gives a foundation for descriptions and redescriptions of fungi in the Glomales. Since its publication more than 24 additional new species have been described (Walker and Trappe, 1992), and new characteristics have been introduced such as the fluorescence of spore walls after reaction with a stilbene fluorochrome (Giovannetti et al, 1991).

\section{THE GLOMALES}

The unifying characteristic of the order is defined as the ability to form arbuscular mycorrhizas. It must be questioned whether such a character can validly define an order.

The ectomycorrhizal habit has evolved several times, and can be found amongst fungi from all 3 classes, Zygomycetes, Ascomycetes and Basidiomycetes. It is at least possible that the arbuscule also has evolved more than once, and until fossil evidence or molecular study shows otherwise, some reservations must be expressed. Certainly the inclusion of the species (or species complex) Glomus tenue (Greenall) Hall must be considered to be doubtful, since it possesses structural polysaccharides different from those of at least some other Glomus spp (GianinazziPearson et al, 1981). There is also one fungus currently placed in the Glomaceae, $G$ tubiforme, which is known to form ectomycorrhizas with species of Eucalyptus (Warcup, 1985). Although this species was excluded from the Endogonaceae on the grounds that the description did not conform well to the type collection (Trappe, 1982),

Table II. Types of walls described so far in the Glomales.

$\mathrm{P}=$ Peridium (outer only. On spore, not on sporocarp)

$X=$ Expanding (outer only. Expands in acidic mountant)

$E=$ Evanescent (outer only. Disappears with time)

$\mathrm{L}=$ Laminated (usually second wall. Often difficult to see laminae)

$U=$ Unit (often outermost. Can be very thin and difficult to see)

$A=$ Amorphous (purple reaction with Melzer's reagent.

Plastic in acidic mounting media)

$\mathrm{C}=$ Coriaceous (flexible, thick. May be laminated)

$M=$ Membranous (flexible, thin. Probably always inner layers)

$\mathrm{G}=$ Germinal (Gigaspora only). examination of authenticated material, kindly sent to me by Dr Warcup shows it to fit with the current phenotypic concept of the genus Glomus. Comparison of this species with arbuscular mycorrhizal fungi through the use of molecular techniques would be enlightening.

Only a small proportion of the $>130$ species from among the 6 genera currently included in the Glomales (Walker and Trappe, 1992), are actually known to be mycorrhizal. Many were described from field collected material. Others were from mixed species open-pot cultures, and therefore mycorrhizal associations are assumed rather than known.

\section{TAXONOMY}

Steussy (1992) discussed the current state of systematics in the Glomales, and concluded that there were 5 areas requiring particular attention. These were the development of "workable taxa", the study of the organisms at the macromolecular level; the re-definition of the classification based on phylogeny, the study of population genetics; and a biogeographical classification. To these could be added to need to engineer a workable method of identifying and recognising individual clones so that the genetic explanations for morphological, physiological and ecological differences can eventually be uncovered. In particular, the link between phenotypic and molecular diversity must be understood, and it must be established whether or not there is environmentally-linked plasticity in spore characteristics (Sen, 1992). It also follows that an effort must be made to re-describe all existing species in a universally acceptable manner. Many described taxa are "workable" in the sense that they are recognisable and are repeatedly found in different parts of the world. There is, however, a problem in the inadequate descriptions of many, especially earlier, species. There are also difficulties, particularly in Glomus, but also in Acaulospora and Scutellospora, of seemingly intergrading species.

\section{GENERA}

There are 6 genera presently included in the Glomales (table I). Although they seem, superficially at least, to be clearly defined and easy to separate (Walker, 1987), their circumscription is 
not unequivocal. A review of their integrity, founded on phylogeny rather than morphology is required unless they are to be treated merely as form genera (Walker, 1985).

\section{Scutellospora and Gigaspora (the Gigasporaceae)}

These are perhaps the most clearly recognisable of the genera (Walker and Sanders, 1986). The correct name for the spores of these 2 genera is controversial. Originally, they were thought to be zygospores (Gerdemann and Nicolson, 1968), but they were later regarded as azygospores (Gerdemann and Trappe, 1984). However, they are probably neither, and should simply be referred to as spores until their identity is unequivocally determined.

The spores are described as being formed on a swollen hyphal tip called a bulbous hyphal attachment (Nicholson and Gerdemann, 1968). This structure has also been called a bulbous suspensor-like cell (Gerdemann and Trappe, 1974) or a sporogenous cell (Spain Sieverding et al, 1989). The bulbous attachment usually bears one or more peg-like structures which subtend an extremely fine hypha that extends towards, and often touches, the surface of the spore. Close examination indicates that, in reality, the bulbous structure is not a cell at all but is continuous with the walls of the remainder of the spore (unpublished observations). The pore connecting it and the "spore" appears not to be occluded, or to be closed only by an indistinct plug of cytoplasmic material. This has been confirmed by the electron-microscopic studies of Sward (1981) for Gigaspora margarita Becker, by Hall and Gibson (1985), for G gigantea (Nicholson Gerdemann) Gerdemann and Trappe, Scutellospora pellucida (Nicholson and Schenck) Walker and Sanders and $S$ gregaria (Schenck and Nicolson) Walker and Sanders. The base of the bulbous structure is continuous with its originating hypha, termed a sporophore by Spain et al (1989). These observations must be confirmed by further ultrastructural and ontogenetic studies, but it seems possible that for both genera, the "spore", including the bulbous structure, is a type of sporangiophore and that a thin-walled sporangium is developed internally. In Gigaspora, no further development of inner walls takes place but in Scutellospora, the process is completed by the formation of a sporangiospore, consisting of 1 or more continuous wall layers within the sporan- gium. This type of structure was suggested by Ferrer and Herrera (1981), though they retained the term azygospore, and called the 3 wall groupings exospore, mesospore and endospore, respectively.

One development stage of Scutellospora spores is indistinguishable from mature spores of Gigaspora. This characteristic led Morton (1990a) to surmise that one is an extant ancestor of the other, and to propose on cladistic theoretical reasoning that these genera should not be separated. Whether this is so or not, in practical terms, they are readily separable, and provide useful supra-specific taxa. Morton believes that Gigaspora is ancestral to Scutellospora, though it seems more likely that the reverse is true. The former seems to be distributed over a much smaller biogeographical range than the latter (unpublished data).

Vesicles are not formed by members of these 2 genera. However, there is 1 report of vesicle formation, recently brought up by Stuessy (1992). Fortunately, these so-called vesicles are adequately illustrated (Furlan and Fortin, 1973). They are clearly auxilliary cells. These structures are occasionally formed within roots, but such an occurrence is rare, and is not analogous to the vesicle formation in vesicular-arbuscular mycorrhizal fungi.

\section{Sclerocystis and Glomus (the Glomaceae)}

Sclerocystis at one time encompassed all species with Glomus-like spores that formed in sporocarps in an orderly manner around a "sterile central plexus" (Gerdemann and Trappe, 1974). However, after a recent revision, it contains only a single species. $S$ coremioides Berkeley and Broome (Almeida and Schenck, 1990). The genus is now defined by having unbranched sporophores formed around a central sterile hyphal plexus, each sporophore bearing a single spore occluded by a basal septum. Inoculation of Zea mays $L$ pot cultures reportedly caused vesicular-arbuscular mycorrhizas to form though evidence for this is circumstantial (Gerdemann and Trappe, 1974). In view of the difficulties of maintaining purity in open pot cultures, it would be wise to treat its mycorrhizal status with some reservation pending verification. The retention of this monospecific genus in the Glomales should be re-considered when more is known of its biology. 
The genus Glomus presents most difficulty. It is almost certainly polyphyletic. Indeed, if it is monophyletic, and the generic classifications are natural, then because Glomus leptotichum Schenck and Smith is a morph of Acaulospora gerdemannii Schenck and Nicholson (=A appendicula Spain, Sieverding and Schenck), all species of the latter must logically be placed in Glomus. This seems unlikely to be correct, and therefore there is a need for a thorough review of the genus. Modern methods such as isozyme analysis and other more sophiticated molecular techniques should be capable of resolving this confusion, but even at the light microscope level some suggestions can be made.

Glomus scintillans Rose et Trappe ( $=G$ dominikii Blaszokowskl) and $G$ lacteum Rose et Trappe both appear to have closer affinity to the Gigasporaceae than to the Glomaceae. The former has an ornamented outer wall, and a flexible inner wall atypical of those in other Glomus spp but similar to some Scutellospora spp. The latter germinates in a manner at least superficially resembling that of species of Gigaspora. Neither of these species fits well with a narrow definition of Glomus.

Amongst the species of Glomus, there are at least 3 distinct lines with regard to occlusion of spore contents. One, respresented by $G$ maculosum Miller and Walker, possesses a complete endospore formed by a more or less flexible inner wall group. Another is represented by $G$ fasciculatum (Thaxter) Gerdenann and Trappe emend Walker and Koske in which the spore is sealed by ingrowth and thickening of the wall of the subtending hypha. In a third group, represented by the $G$ mosseae complex, occlusion is by a septum usually somewhat distal to the spore base. The significance of occlusion in Glomus merits further investigation.

There are also 2 known modes of germination in the genus Glomus. In one (generally accepted as the norm for the genus), a new hypha emerges through the lumen of the spore's subtending hyphae. In the other, germination is by way of a germ tube emerging directly though the spore wall. In reality, the germination mode is known for only a very few species in the genus. Germination must be characterised for as many species as possible to determine if these modes are mutually exclusive and to assess their phylogenic significance.

\section{Acaulospora and Entrophospora (the Acaulosporaceae)}

Acaulospora is clearly defined morphologically by the production of spores laterally on the proximal part (often referied to as the neck) of a sporiferous saccule. But there must be some doubt about its integrity on phylogenetic grounds. There are at least 2 distinct lines. In one, spores are hyaline, generally very small, and possess neither an amorphous wall, nor beading on an inner flexible wall. In some species, the saccule neck clearly surrounds the spore, and often is seen as an apparent external wall. This method of formation has not, however, been observed for all species, and it is possible that in some, the spore forms externally on, rather than in, the saccule neck. Ultrastructural and ontogenetic studies are needed to clarify this.

The genus Entrophospora is defined by the type species, $F$ infrequens (Hall) Ames and Schneider. There are presently only 2 other species, $E$ schenckii Sieverding and Toro and E colombiana Spain and Schenk. Other than the formation of spores inside the saccule neck, they bear little resemblance to each other, and the presence of 2 scars (cicatricula) on $E$ colombiana may indicate a fundamental difference in spore formation from those of the type species, which has only one.

\section{Clones, species and groupings}

Stuessy (1992) raised the question as to whether the term "species" was appropriate at all for asexual organisms, suggesting that 'clone' might be more useful. But species and clone are terms of different sorts, one being a taxonomic level of classification which can include great diversity of genotype, the other being a definition of genetic identity.

Each spore of an arbuscular mycorrhizal fungus contains many (possibly thousands) of nuclei (Burggraaf and Beringer, 1989), and it is not yet certain that these are of a single genotype. As Steussy points out, clones are genetically identical individuals derived from 1 parent. Offspring of a single spore may be of one parent, but there is no certainty that they are of a single genotype. Thus, until more is known about fungal karyotype in the Glomales, the term clone seems insuitable for use even with pot cultures established from a single pore. However, there 
are two words, 'genet' and 'ramet' that can be applied to fungi (Brasier and Rayner, 1987). The former is defined as a genetically discrete unit or assemblage, whilst the latter (equivalent to a clone) results from asexual or vegetative propagation of a genet. By this definition, any sample of a fungus (providing it is derived from only one fungal thallus) from the field is a ramet. Once a single-spore or pure culture is established from a ramet, it becomes an isolate, which produces, on subsequent asexual propagation, a strain, providing it consists of a homokaryotic mycelium (Ainsworth and Bisby, 1983). In the Glomales, this last constraint suffers the same objections as that discussed for a clone above. It is not yet certain that even a single-spore isolate is homokaryotic.

Many cultures of fungi in the Glomales are obtained through a process of open-pot culture (Gilmore, 1968). Whilst this often results in apparently pure cultures producing spores of indistinguishable morphology, here. is no certainty that only one genotype exists. Indeed, there is evidence that a single plant can form a symbiosis with more than one fungus (Rosendahl et al, 1989), and little is known about the competition among genets of arbuscular mycorrhizal fungal species. Only after single-spore cultures are established, can the term isolate (or clone) properly be used and then only if it is assumed that the nuclei in the spore are of but a single genotype.

To overcome these objections, two other terms, taken from the terminology of forestry origin and provenance - might be considered for use among the Glomales. For a tree, origin designates the original (indigenous) seed source. The origin (geographic) of a pot culture might thus be identified with no implication of its genotypic purity. The provenance in forestry refers to the actual geographic source of seed. Thus, a spruce with a provenance of the west of Scotland may have had its origin in the Queen Charlotte Islands in the US Northwest Pacific. With a pot-cultured arbuscular mycorrhizal fungus, its culturing history could be indicated partly by using the name of the institution at which it is maintained as its provenance. Thus, one of the most commonly used cultures of Glomus mosseae (Nicol and Gerdemann) Gerdemann and Trappe would have its origin as a field in Kent, but would have many different provenances. Changes through genetic drift or molecular drive (Dover, 1982) induced by different culturing conditions might then be recognised by comparing cultures of common origin but different provenance.
Again, referring to Stuessy (1992), there is a suggestion that it might be appropriate to adopt a purely phenetic species concept. This is, largely the current position with the Glomales, though in the original sense of a system which takes account of as many characteristics as possible without considering one to be more important than the other, rather than in Stuessy's definition equating the term with numerical taxonomy. However, this position is changing as characteristics such as differences in ontogeny are used to delimit species (Morton, 1988; Giovanetti et al, 1991). There are practical reasons for maintaining the phenetic approach for the present, despite the undoubted merit of the plea for a truly phylogenetic system. Although it is no doubt desirable that identifications be made only from pure pot cultures containing all development stages of spore ontogeny, in reality, much of the material people wish to identify is collected either from the field or from mature pot cultures too old to show developmental sequences. Developments in molecular techniques may lead to a 2tier system, one based on morphology, which provides a workable taxonomy allowing identification to species through careful use of a good quality light microscope (Koske and Walker, 1985), and the other, with molecular techniques such as study of rDNA variation (eg Chen et al, 1984; LoBuglio et al, 1990; Waters et al, 1992), which will provide a cladistic framework for a phylogenetic systematics.

Clearly, because these fungi are mainly, if not exclusively, asexual organisms, the definition of species cannot be based on interbreeding. It is probably best to accept a purely phenotypic definition to provide a workable concept for species that can be used without access to anything more sophisticated than a good microscope. It should be stressed that careful and accurate observation is a prerequisite. Such a system should provide a basis for separation below species level on other characteristics such as biochemistry. Its value is demonstrated by the evidence that the better-defined morphological species can be identified from widely separated parts of the world. For example, Acaulospora elegans Trappes and Gerdemann, originally described from the US Pacific Northwest (Gerdemann and Trappe, 1974), also occurs in Scotland (Walker, personal herbarium accession No 1502).

The species which appear to intergrade might be thought of temporarily as groupings until study has shown whether or not they are discretly identifiable. Thus, Glomus mosseae, $G$ mono- 
sporum Gerdemann and Trappe, G dimorphicum Boyetchko and Tewari, $G$ fecundisporum Schenck and Smith and possibly some other Glomus spp have many similarities, and may well be conspecific. Until more is known about their true relationships, they can be thought of as forming a group. Similarly Acaulospora scrobiculata Trappe, $A$ paulineae Blaszkowsky, and $A$ undulata Sieverding appear to be part of a range of morphology which, pending clarification, should be considered as a species group rather than a species. The use of the term group would draw attention to the taxonomic problems associated with the species. Nevertheless, grouping must be on a logical morphological basis. An example of an untenable grouping was discussed when Glomus fasciculatum was re-described (Walker and Koske, 1987).

For clones, it is clear that morphology will not be of value, except to place the clone in a classicaly-defined species. Even single spores will have more than one nucleus, and since the fungi evolved early, they may have the primitive characteristic of possessing polykaryotic or oligokaryotic mycelium (Prillinger, 1987). Only when reliable methods of characterisation and registration of cultures are available will the assured use of clones become realistic, and this will only be biologically useful if scientists become prepared to check isolates for purity both before and after use in experiments.

A major step towards the clonal approach advocated by Morton (1990a) and quality-control approach suggested here, could be made by introducing a world-wide registration scheme such as is used by scientists working on Frankia spp (Lechevalier, 1982). This should start with morphospecies and origin, and moving through provenances of genets and isolates and finally to strains. This would allow all available information of any registered culture to be accumulated and made readily accessible.

\section{Molecular studies}

Molecular studies are likely to become crucial in characterisation of isolates of fungi from the Glomales. Apparent species specific $18 \mathrm{~S}$ ribosomal genes have been sequenced for 2 species, Glomus intraradices and Gigaspora margarita (Simon et al, 1992). Ideally, such characterisation should be made for each species to allow a full phylogenetic analysis, but, disregarding the fact that many species have not been found again since their original description, the process is expensive and requires highly specialised equipment. The opinion that such techniques will be used to supplement, rather than replace taxonomic systems based on morphology (MooreLandecker, 1982) will remain valid at least for the near future.

\section{Phylogenetic classification}

Although a start has been made on the classification of these fungi (Morton and Benny, 1990), it needs verification through extensive study of their molecular biology and population genetics. A prerequisite to this is the isolation of genets of different origins for (morpho)species, along with the development of routine methods for their identification. Such germplasm is extremely valuable and should whenever possible be preserved for the use of future researchers. There is a need for close cooperation between taxonomists and molecular biologists.

\section{Biogeography}

The study of biogeographical distribution demands that the taxonomy be sufficiently advanced to recognise discrete species. From existing concepts, it seems that some 'species' have a very wide distribution, but these are often those which seem to form groups such as $A$ scrobiculata and $G$ mossea. Some clearly defined species such as $A$ elegans have been found on different continents, whereas others (eg $S$ scutata Walker and Diederichs) seem to be more confined. Even at genus level, there may be geographical differences. For example, in almost 2 decades of study, I have never yet seen a species of Gigaspora from northern Europe, and species of Scutellospora appear to be more diverse in tropical than in temperate conditions. However, confirmation of trends such as this must await a more systematic search and must include preservation of voucher specimens for verification of identification.

\section{THE TYPE CONCEPT}

Type material is the sample, lodged in an internationally accredited herbarium, upon which the 
species description is based. Lodging types is controlled by international agreements expressed in the International Code of Botanical Nomenclature. It is important to recognise that type material need not be typical of the species. This may seem a peculiar anomaly, but the type is merely the first example of the species, being simply the specimen used to make the species description. Because it is only one sample from a population, there is a probability that it will not be typical. Later specimens will allow the central tendencies and boundaries of the species to be defined. It is worth remembering that neither specimens nor cultures constitute a species, but are merely samples from among the population that forms it.

The Botanical Code of Nomenclature requires that dead specimens be deposited as type material. Indeed, it specifically excludes the use of living plants or cultures. Specimens in fixatives and preservatives can never give us the information needed to develop a phylogenetic classification of these obligate symbionts. But for members of the Glomales, there seems no reason why living material, at least in the form of dried pot culture substrate, should not be deposited along with the permanently preserved type specimens. Such specimens may then the used for later DNA analysis.

Even when the rules of the Botanical Code are followed, the species descriptions must be adequate to allow others to identify the organism. A species description such as that of Glomus reticulatum (Bhattacharjee and Mukerji, 1980 ) is of little value, especially when requests for loan of type material go unanswered. In addition, characteristics such as the effects of decay or parasitism have been used in species descriptions as a result of describing new taxa from dead field material (Bhattacharjee et al, 1982), and species descriptions should ideally be made from living specimens.

The observations needed for definite identification of a new species can rarely be made on only a single spore. Usually, it is necessary to have a series of at least a dozen (from a singlespecies pot culture) or perhaps many more (from field soil). Indeed, whilst it is sometimes possible to identify species from field samples, it is extremely difficult, and many spores will not be able to be identified with certainty. Nevertheless, biogeographical studies of species will depend on identification of field collected material. For this type of study, herbarium specimens with ac- companying notes and illustrations of characteristics such as reaction to Melzer's reagent and mounting media should be preserved.

\section{DISAGREEMENT ON TERMINOLOGY}

Minor disagreements over terminology can be ignored, but where there are real doubts expressed, as, for example, by Berch (1986), Spain et al (1989) or Spain (1990) they must be addressed. In view of the small number of workers in this field, it would seem a good idea to discuss any changes before publishing.

Wall structure is now an important feature, but the terminology is imprecise and complex. There is a need to distinguish walls from wall-layers. This will be dependent on the clarification of spore development, and will require ultrastructural and ontogenetic studies.

\section{THE WAY FORWARD}

One of the crucial propositions put forward by Steussy (1992) is that 'some agreement in the community' needs to be achieved, and he suggests the establishment of a working group for this purpose. This is a timely proposal but such a group must be fully representative of the few taxonomists active in this area.

A group of workers in the European Community have proposed a system for the identification, registration, care, and distribution of living isolates of endomycorrhizal fungi. The proposal goes beyong taxonomy and has the following aims:

- to establish a registration scheme for pot cultures of fungi in the Glomales and to build a history of their distribution and use;

- to establish a Bank Without Walls, of registered cultures, to ensure their free exchange and encourage concerted research effort;

- to build and maintain a database of these isolates so that accumulated information can be recorded and distributed as required;

- to provide a central repository for germ plasm preservation;

- to offer an identification and registration scheme which will enhance the quality of endomycorrhizal research throughout Europe, and lead to more efficient use of funding by integration; 
- to provide a service that will underpin the industrial exploitation of endomycorrhizal technology, by setting standards of quality control for fungal inoculum;

- to increase the distribution of knowledge of taxonomy and systematics of the Glomales in Europe through training, workshops, and publications.

This "Bank Without Walls" will consist of laboratories that have agreed to maintain 3-5 living pot cultures to be made available to participants on request. The central database and registration scheme will accept and register mixedspecies or single-species cultures. Re-isolation into single spore cultures will be encouraged. The provision of serial registration numbers will allow all future information on the isolates and strains to be accumulated in the database. Such information will then be immediately available to all participants.

It is envisaged that taxonomic services will be offered centrally for identification, long-term preservation of germ plasm and the curation of verified specimens in an internationally recognised herbarium. An important service of a culture purity and identification check would be offered, so that isolates used in experiments can be verified, at least to species, and voucher specimens preserved, both before and after an experiment is performed. Ideally, cultures would be received centrally and re-isolated from single spores to assure their purity. This would give participants confidence when comparing results of research on the registered cultures.

\section{STANDARDISATION}

It would be helpful if a standardised procedure for species description is developed so that both new species and re-descriptions become more easily comparable. Although new taxonomic characteristics might be found, it is likely that most of the important ones are already known. For example, descriptions should proceed from larger features to smaller; from more obvious characteristics to those that are less so.

Spore colour is an important characteristic in identification of species in the Glomales. There is a need for a standardised colour chart, but there are great difficulties in our colour matching, largely related to the differences in perception from person to person, and in the different sources of illumination. Whilst it is possible to use split fibre optics to illuminate both specimen and chart when observing through a dissecting microscope, no such comparisons can be made with a compound microscope. Hence, whilst colour comparisons can be carried out with relative accuracy from intact spores suspended in water, colours of walls, cytoplasmic contents, etc seen through a compound scope cannot be matched accurately.

Wall structure descriptions are important (table I), but experience has shown that the concepts used are difficult to understand and inconsistently applied. With so few scientists actively engaged in making species descriptions, it should not be difficult for full discussion to take place before any new terminology is introduced, although this requires the relinquishing of some individual rights for the benefit of the community. As originally proposed (Walker, 1983), the concept was intended to be an entirely artificial aid to species description in a phenetic system. Its use in a phylogenetic classification is valid only if the recognised wall types are homologous among species and genera. The phenomenon of convergence is common in the Glomales (Morton, 1990b) and thus there is a need to establish homologies and analogies within morphologically similar walls in different fungi. For example, the membranous walls found in species of Scutellospora are unlikely to be homologous with those in Glomus.

\section{CONCLUSION}

The considerable expenditure of both time and money in research into the effects of these fungi needs to be supported by a workable and predictitive taxonomy. This taxonomy ideally should be based on phylogeny, supported by morphological, ontogenetic, biological, molecular and genetic studies. Its present foundation in spore morphology has little predictive value, but could be usefully maintained and improved to provide a starting point for more biologically meaningful characterisations, as well as for field studies of species diversity. Improved international cooperation among taxonomists should be encouraged to reach agreement on standardised descriptions and terminology. Such cooperation should occur before rather than after publication.

The identification of fungi in the Glomales is a difficult and specialised task. A central service for the identification, characterisation, and regis- 
tration of cultures would allow and encourage much greater standardisation, and bring with it a high degree of quality control, along with the opportunity to store, cross-reference, and broadcast results for more efficient use of research funds.

\section{ACKOWLEDGMENTS}

The COST 8.10 grouping of the European Economic Community under the charimanship of S Gianinazzi is acknowleded for stimulting this review. In particular, the many helpful discussions of the participants of Working Group VIII are acknowledged.

\section{REFERENCES}

Almeida RT, Schenck NC (1990) A revision of the genus Sclerocystis (Glomaceae, Glomales). Mycologia $82,703-714$

Bécard G, Piché $Y$ (1989) New aspects on the acquisition of biotrophic status by a vesicular-arbuscular mycorrhizal fungus, Gigaspora margarita. New Phytol 112, 77-83

Benjamin RK (1979) Zygomycetes and their spores. The Whole Fungus (Kendrick B, ed) Nat Mus Canada, Ottawa, vol 2, 573-622

Berch S (1986) Endogonaceae: taxonomy, specificity, fossil record, phylogeny. Front Appl Microbiol 2, 161-188

Bhattacharjee M, Mukerji KG (1980) Studies on Indian Endogonaceae. II. The genus Glomus. Sydowia, Ann Mycol Ser II, 33, 14-17

Bhattacharjee M, Mukerii KG, Tewari JP, Skoropad WP (1982) Structures and hyperparasitism of a new species of Gigaspora. Trans Mycol Soc 78, 184-188

Brasier CM, Rayner DM (1987) Whither terminology below the species level in fungi? In: Evolutionary Biology of the Fungi (Rayner ADM, Brasier CM, Moore D, eds) Cambridge Univ Press, Cambridge UK, 379-388

Burdsall HH (1990) Taxonomic mycology: concerns about the present; optimism for the future. Mycologia 82, 1-8

Burggraaf AJP, Beringer JE (1989) Absence of nuclear DNA synthesis in vesicular-arbuscular mycorrhizal fungi during in vitro development. New Phytol 111, 25-33

Chen MW, Anné J, Vockaert G, Huysmans E, Vandenberghe A, Wachter R De (1984) The nucleotide sequences of the $5 S$ rRNAs of seven molds and a yeast and their use in studying ascomycete phylogeny. Nucleic Acids Res 12, 4881-4892

Dover G (1982) Molecular drive a cohesive mode of species evolution. Nature 299, 111-117

Ferrer RL, Herrera RA (1981) El genero Gigaspora Gerdemann et Trappe (Endogonaceae) en Cuba. Rev Jard Bot Nac Habana 1, 43-66
Furlan V, Fortin JA (1973) Formation of endomycorrhizae by Endogone calospora on Allium cepa under three temperature regimes. Nat Can 100, 467-477

Gerdemann JW, Nicolson TH (1963) Spores of mycorrhizal Endogone species extracted from soil by wet sieving and decanting. Trans Br Mycol Soc 46, 235-244

Gerdemann JW, Trappe JM (19) The Endogonaceae in the Pacific Northwest. Mycol Mem No 5,

Gianinazzi-Pearson V, Morandi D, Dexheimer J, Gianinazzi $S$ (1981) Ultrastructural and uttracytochemical features of a Glomus tenuis mycorrhiza. New Phytol 88, 633-639

Gibson JL (1985) Morphology, cytology and ultrastructure of selected species of Endogonaceae (Endogonales: Zygomycetes). $\mathrm{Ph} \mathrm{D}$, Univ Florida

Gilmore AE (1968) Phycomycetous mycorrhizal organisms collected by open-pot culture methods. Hilgardia 39, 87-105

Giovannetti M, Avio I, Salutini L (1991) Morphological, cytochemical and ontogenetic characteristics of a new species of vesicular-arbuscular mycorrhizal fungu. Can J B 69, 161-167

Hall IR (1983) A summary of the features of endogonaceous taxa: third edition. Tech Rep No 8, Invermay Agric Res Centre, Mosgeil, NZ

Hall IR (1987) Taxonomy and identification of vesicular-arbuscular mycorrhizal fungi. Zeitsch Angew Bot $61,145-152$

Hall IR, Fish BJ (1979) A key to the Endogonaceae. Trans Br Mycol Soc 73, 261-270

Koske RE, Walker C (1985) Species of Gigaspora (Endogonaceae) with roughened outer walls. Mycologia $77,702-720$

Lechevalier MP (1983) Cataloging Frankia strains. Can J Bot 61, 2964-2967

LoBuglio K, Rogers SO, Wang CJK (1990) Variation in ribosomal DNA among isolates of the mycorrhizal fungus Cenococcum geophilum. Can J Bot 69, 2331-2343

Moore-Landecker E (1982) Fundamentals of the Fungi. Prentice-Hall, $\mathrm{NJ}$, 2nd edn

Morton JB (1987) Effects of mountants and fixatives on wall structures and Melzer's reaction in spores of two Acaulospora species (Endogonaccae). Mycologia 78, 787-794

Morton JB (1988) Taxonomy of VA mycorrhizal fungi: classification, nomenclature, and identification. $M y$ cotaxon 32, 267-324

Morton JB (1990a) Species and clones of arbuscular mycorrhizal fungi (Glomales, Zygomycetes): their role in macro- and microevolutionary processes. Mycotaxon 37, 493-515

Morton JB (1990b) Evolutionary relationships among arbuscular mycorrhizal fungi in the Endogonaceae. Mycologia 82, 192-207

Morton JB, Benny GL (1990) Revised classification of arbuscular mycorrhizal fungi (Zygomycetes): a new order, Glomales, two new suborders, Glomineae 
and Gigasporineae, and two new families, Acaulosporaccae and Gigasporaceae, with an emendation of Glomaceae. Mycotaxon 37, 471-491

Mosse B (1953) Fructifications associated with mycorrhizal strawberry roots. Nature 171, 974

Mosse B, Bowen GD (1968) A key to the recognition of some Endogone spore types. Trans Br Mycol SoC $51,469-483$

Nicolson TH, Gerdemann JW (1968) Mycorrhizal Endogone species. Mycologia 60, 313-325

Prillinger $H$ (1987) Yeasts and anastomoses: their occurrence and implications for the phylogeny of Eumycota. Evolutionary Biology of the Fungi (Rayner ADM, Brasier CM, Moore D, eds) Cambridge Univ Press, 355-377

Rosendahl S, Rosendahl CN, Søchting U (1989) Distribution of VA mycorrhizal endophytes amongst plants from a Danish grassland community. Agric Ecosyst Environ 29 (B), 329-336

Sen R (1992) Isozyme analysis of mycorrhizal fungi and their mycorrhiza in identification, population biology and competition studies. Univ Helsinki, Finland

Simon L, Lalonde M, Bruns TD (1992) Specific amplification of $18 \mathrm{~S}$ fungal ribosomal genes from vesicular-arbuscular endomycorrhizal fungi colonizing roots. App/ Environ Microbiol 58, 291-295

Spain JL (1990) Arguments for diagnoses based on unaltered wall structures. Mycotaxon 38, 71-76

Spain JL, Sieverding E, Schenck NC (1990) Gigaspora ramisporophora: a new species with novel sporophores from Brazil. Mycotaxon 34, 667-677

Steussy TF (1992) The systematics of arbuscular mycorrhizal fungi in relation to current approaches to biological classification. Mycorrhiza 34, 667-677

Sward RJ (1981) The structure of the spores of Gigaspora margarita. I. The dormant spore. New Phytol 87, 761-768
Thaxter $R$ (1992) A revision of the Endogonaceae. Proc Am Acad Arts Sci 57, 291-351

Trappe JM (1982) Synoptic keys to the genera and species of zygomycetous mycorrhizal fungi. Phytopathology 72, 1102-1108

Walker C (1983) Taxonomic concepts in the Endogonaceae: spore wall characteristics in species descriptions. Mycotaxon 18, 443-455

Walker C (1985) Taxonomy of the Endogonaceae. In: Proc 6th North Am Conf Mycorrhizae (Trappe JM, Molina R, Berch SM, eds) 193-199

Walker C (1987) Formation and dispersal of propagules of endogonaceous fungi. In: Fungal Infection in Plants (Pegg G, Ayers, P, eds) Cambridge Univ Press, 269-284

Walker C, Koske RE (1987) Taxonomic concepts in the Endogonaceae: IV. Glomus fasciculatum redescribed. Mycotaxon 30, 253-262

Walker C, Sanders FE (1986) Taxonomic concepts in the Endogonaceae: III. The separation of Scutellospora gen nov from Gigaspora Gerd and Trappe. Mycotaxon 27, 169-182

Walker C, Trappe JM (1992) Names and epithets in the Glomales and Endogonales. Mycol Res 96 (in press)

Walker C, Reed LE, Sanders FE (1984) Acaulospora nicolsonii, a new endogonaceous species from Great Britain. Trans Mycol Soc 82, 359-364

Warcup JH (1985) Ectomycorrhiza formation by Glomus tubiforme. New Phytol 99, 267-272

Warcup JH (1990) Taxonomy, culture and mycorrhizal associations of some zygosporic Endogonaceae. Mycol Res 94, 173-178

Waters DA, Buchheim MA, Dewey RA, Chapman RL (1992) Preliminary inferences of the phylogeny of bryophytes from nuclear-encoded ribosomal RNA sequences. Am J Bot 79, 459-466 